\title{
Memory Monitoring and Control in Young and Intermediate-Age Adults ${ }^{1}$
}

\author{
Maxciel Zortea ${ }^{2}$ \\ Universidade Federal do Rio Grande \\ do Sul, Porto Alegre-RS, Brazil
}

\author{
Graciela Inchausti de Jou \\ Universidade Federal do Rio Grande \\ do Sul, Porto Alegre-RS, Brazil
}

\author{
Jerusa Fumagalli de Salles \\ Universidade Federal do Rio Grande \\ do Sul, Porto Alegre-RS, Brazil
}

\begin{abstract}
The way adults perceive and regulate learning (metamemory) is an important indicator of how they perform on memory tasks. This study assessed memory monitoring, control and performance in young and intermediate-age adults according to item type (with or without semantic relation), type of judgment of learning (JOL - immediate or delayed), and age. Twenty-six young adults $(M=22$ years old) and 18 intermediate-age adults $(M=47$ years old) participated, who responded to an experimental paradigm to evaluate metamemory. Results showed that related word-pairs received higher magnitude for the JOLs and better cued-recall scores. JOLs' accuracy was similar between the age groups, delayed JOLs being more accurate only for young adults. Intermediate-age adults apparently based their allocation of study time less on JOLs or cued-recall than young adults.
\end{abstract}

Keywords: metacognition, memory, developmental age groups

\section{Monitoramento e Controle de Memória em Adultos Jovens e de Idade Intermediária}

\begin{abstract}
Resumo: A maneira como adultos percebem e regulam a aprendizagem (metamemória) é importante indicador de como desempenham tarefas de memória. O objetivo deste estudo foi avaliar o monitoramento, o controle e o desempenho de memória em adultos jovens e de idade intermediária conforme tipo de item na tarefa (pares de palavras com e sem relação semântica), o momento em que os JOLs foram feitos (JOLs imediatos e tardios) e idade. Participaram 26 adultos jovens $(M=22$ anos) e 18 adultos de idade intermediária $(M=47$ anos), que responderam a um paradigma experimental de metamemória. Observou-se que pares de palavras relacionados levaram à maior magnitude dos JOLs e melhores escores na evocação com pista. A precisão dos JOLs foi semelhante para os grupos etários, sendo JOLs tardios mais precisos apenas para adultos jovens. Adultos de idade intermediária contaram menos com seus JOLs ou com a evocação com pista para guiar o tempo de reestudo do que adultos jovens.
\end{abstract}

Palavras-chave: metacognição, memória, grupos etários

\section{Monitoreo y Control de Memoria en Adultos Jóvenes y de Edad Intermediaria}

\begin{abstract}
Resumen: La forma en que los adultos perciben y regulan el aprendizaje (metamemoria) es un indicador importante de cómo ejecutan tareas de memoria. La finalidad de este estudio fue evaluar el monitoreo, control y desempeño de memoria en adultos jóvenes y de edad intermediaria de acuerdo al tipo de estímulo (pares de palabras con o sin relación semántica), tipo de juzgamiento de aprendizaje (JOL - inmediato y retrasado), y edad. Participaron 26 adultos jóvenes $(M=22$ años de edad) y 18 adultos de edad intermediaria $(M=47$ años), que respondieron a un paradigma experimental de metamemória. Fue observado que los pares de palabras relacionadas condujeron a un aumento de magnitud de los JOLs y una mejor recuperación con pista. La precisión de JOL fue similar en ambos grupos de edad, siendo que JOLs retrasados tuvieran mayor precisión sólo para adultos jóvenes. Adultos de edad intermediaria parecen haber basado su tiempo de re-estudio menos en sus JOLs o recuperación con pista que los adultos jóvenes.
\end{abstract}

Palabras clave: metacognición, memoria, grupos por edad

The study on our ability to think about our own memory, termed metamemory, has important implications for education (Koriat, 2012) and human development (Hertzog \& Dunlosky, 2011). Nelson and Narens (1990) proposed an information

\footnotetext{
${ }^{1}$ Article from the first author's doctoral dissertation under the supervision of the last and co-supervision of the second, defended in 2014, in the Graduate Program in Psychology of the Universidade Federal do Rio Grande do Sul.

Support: Rio Grande do Sul State Research Foundation - FAPERGS (Processes no. 1012868 and 09/0869-9), and the Coordination for the Improvement of Higher Education Personnel (CAPES), (Doctoral grant from the Federal Universities Restructuring and Expansion Program (REUNI)).

2 Correspondence address:

Maxciel Zortea. Rua Ramiro Barcelos, 2600, $1^{\circ}$ andar, sala 114. Santa Cecília. CEP 90035-003. Porto Alegre-RS, Brazil. E-mail: max.zortea@gmail.com
}

processing model for understanding the mechanisms of metamemory, which considers two levels: object (the processing of memory) and meta (knowledges and strategies related to memory and a dynamic representational model of the object level). The information flows between the levels through two processes: memory monitoring, in which the meta level is informed regarding what occurs in the object level; and memory control, which modifies and regulates the activity of the object level. These processes are important in various situations of learning and memorization in the day-to-day. A student can monitor (through metacognitive judgments) how much she has learned on a specific subject which was studied, and control (through the study time) how much she still needs to study in order to master the topic. The evaluation 
of the monitoring and of the control of memory online, that is, while the learning takes place, provides a unique situation for understanding how people think about the codification of information and the relation of this with the regulation of the learning (Dunlosky \& Metcalfe, 2009). Similarly, these processes may be investigated in relation to development, as they influence memory and learning strategies in the different phases of the lifespan (Dunlosky \& Connor, 1997). This introduction will address studies on monitoring and control of memory, as well as the relation between these processes, and how they differ according to age.

In relation to the memory monitoring, it is understood that metacognitive judgments are naturally inferential (Koriat, 2007). That is, the individual applies heuristic reasoning and makes use of various cues, so as to assess the probability of an item of information being recovered. Judgments of learning (JOLs) consist of estimates obtained through self-reporting on scales (Ariel, Dunlosky, \& Bailey, 2009; Carroll, Nelson, \& Kirwan, 1997), regarding the probability of remembering a previously-studied item of information in a subsequent test. These estimates are based on cues, such as the relation between the words of an item in an associative learning task with pairs of words (Koriat, 2007). Pairs with semantically-related words (table - chair) tend to produce a greater magnitude of JOLs (that is, people judge them to be more likely to be remembered) than pairs of words which are not related (dog - spoon) (Carroll et al., 1997). As this facilitation in the JOLs is also found in the performance of memory (Koriat, 2007), this sensitivity effect of the JOLs (greater magnitude for semantically-related pairs) is considered an important cue for understanding how judgments are made.

The JOLs are also evaluated through measurements of accuracy, which reveals how accurate the judgments are in predicting memory performance. The JOLs, therefore, can be evaluated according to elements which influence their sensitivity and by the adjustment of the performance prediction (accuracy). In this concept, one can distinguish relative accuracy, which refers to the extent that the metacognitive judgment predicts the memory performance for one item in relation to another (Dunlosky \& Metcalfe, 2009). This is a measure of ability to discriminate between items which are more, or less, likely to be recovered. There is also absolute accuracy, which refers to the extent of correspondence between the mean rate of metacognitive judgments and the level of general memory performance. It is a measurement of the relation between the quantity of information predicted and remembered. For example, a participant may have attributed high JOLs to some items, which were correctly recalled, and low JOLs to others, which were not recalled; this indicates good relative accuracy. However, if $40 \%$ of the items were recalled in the test, although, on average, the participant judged that she would remember $60 \%$ of the items, this would indicate reduced absolute accuracy, as a result of overestimating.
The point at which the JOLs are made may systematically influence their accuracy. Delayed JOLs undertaken in a period from seconds to days after the study phase, lead to greater relative accuracy in predicting memory performance than the immediate JOLs, undertaken during or immediately after the study (Rhodes \& Tauber, 2011). However, the sensitivity effect (the difference in the judgments for pairs which are, or are not, semantically related) may not be observed in delayed JOLs. Carroll et al. (1997) observed that the magnitude of delayed JOLs one day after the study phase did not differ between pairs of words which were, or were not, related to each other. In the present study, it was sought to understand how this occurs for delayed JOLs with an interval after the study phase of some minutes (15 to 20 minutes), so as to understand whether the sensitivity for pairs which are, and are not, semantically related occurs at intermediate intervals, with JOLs delayed by a short time interval after the study phase. The hypothesis is that this sensitivity effect will be found only for intermediate JOLs, taking into account that the semantic relationship becomes a less salient cue during delayed JOLs (Carroll et al., 1997). As the delayed JOLs are more remote from the study phase and from the intrinsic aspects of the item (as is the case of the semantic relationship), these judgments should have greater relative accuracy, although they should not differ according to the type of item.

According to Nelson and Narens' model (1990), monitoring and control are closely related. The control must be assessed through the study-time allocation (STA) which is obtained, among other means, by the time which the person dedicates to studying a subject to be recovered. The "monitoring affects control" hypothesis (Thiede \& Dunlosky, 1999) suggests that the perception of difficulty/ease regarding an item is essential for directing STA. Thiede and Dunlosky proposed that control occurs due to a reduction of the discrepancy between what was learned and the norm of study, which refers to the goals established by the individual for ideal learning (Thiede \& Dunlosky, 1999). Other factors such as the restriction of time and rewards may mediate this relationship (Ariel et al., 2009). There is, however, expectation that individuals will base STA on the perceived difficulty of the item when the instruction is merely "remember as many items as possible", as was used in this study.

Besides these factors, age may have an important role in the metamnemonic functioning (Ofen \& Shing, 2013). In relation to the memory monitoring, the accuracy and magnitude of metacognitive judgments can vary according to age. Connor, Dunlosky and Hertzog (1997) ascertained that both young people (mean of 20 years old) and older adults (mean of 71 years old) presented similar relative accuracy for immediate JOLs. The same occurred for delayed JOLs, and there were no differences for pairs of words which were, or were not, semantically related. However, they showed differences of age in absolute accuracy, in that memory 
performance was overestimated by the older adults. In a second experiment, when memory recall was facilitated (through the re-presentation of the items), the absolute accuracy of the JOLs was more realist in this age group, in comparison with the previous experiment. The authors believe that other factors, not related to the online process of the JOLs, but which influenced the recall, may have led to these differences, such as intralist interference effects, retention intervals, etc. The absolute accuracy, differently from the relative accuracy, seems to be sensitive to these factors, thus being less determined by the online monitoring, and more by factors which increase or reduce the quantity of information recalled. A high absolute accuracy would occur when these factors were predicted in JOLs, which seems to be impaired in older adults.

Other studies have investigated the role of age in memory control. Dunlosky and Connor (1997), who used unlimited time for restudying pairs of words, tested the differences between young people (mean age of 22 years old) and older adults (mean age of 67 years old) for the STA. They evaluated the "monitoring affects control" hypothesis through the relationship between the time spent restudying the pairs and the magnitude of the JOLs, and the relationship between the time spent restudying and the score for cued recall prior to restudying. Dunlosky and Connor observed that the individuals spent more time restudying items which were judged as less likely to be recovered or which had not been correctly recovered previously, this being in accordance with the idea of reduction of discrepancy between what was learned and the norm of study (Thiede \& Dunlosky, 1999). Young adults, however, relied more on their JOLs to guide the time spent restudying than did older adults. The STA based on the cued-recall did not differ between the groups. The authors suggest that older adults undertake a less-adapted control than do the young adults, due to their greater difficulty in self-initiating coordination between monitoring and control processes. One question as yet unanswered is: do these changes appear only after the age of 60 , or before?

It is known that improvements can occur in the memory capacity of the young adult stage and intermediate-age adult (Martin \& Zimprich, 2005). In one of the few studies on metamemory in this age range, Johnson and Halpern (1999) found that adults with ages between 35 and 50 years old showed greater accuracy of the JOLs for global predictions of performance (questions on a previously-read text) in comparison with young adults aged from 18 to 22 years old. This result indicates lower overestimation on the part of this age group in comparison with young adults and older adults. Therefore, the hypothesis is raised of the greater accuracy of the JOLs in intermediate-age adults, in comparison with young adults. There is also the expectation of greater use of monitoring for guiding the time allocated to studying. The objective of the study was to evaluate the monitoring, the control, and the performance of memory in young and intermediate-age adults, in accordance with the type of item in the task (pairs of words which are, and are not, semantically related), the point at which the JOLs were made (immediate and delayed JOLs) and age.

\section{Method}

\section{Participants}

A total of 44 individuals participated in this study. Two groups were constituted, according to the distinct age ranges. That these were undergraduate students and teachers occurred as a result of the fact that sampling was by convenience, as well as because of the search to maintain similar educational levels (one group with higher education incomplete, and one with higher education complete). The group of young adults consisted of 26 undergraduate students from a public university (16 of Psychology, four of Dentistry, four of Nutrition, one of Physiotherapy, and one of Physical Education), with a mean age of 22.4 years old ( $S D=2.9$; from 19 to 29$), 12.9$ years of study $(S D=1.6$ ), these being 18 women. The group of adults of intermediate age was made up of 18 teachers from the public network of junior high education (16 women), all with higher education complete, with a mean age of 47.6 years old $(S D=11.6$; between 28 and 65$) ; 17.5$ years of study $(S D=1.9)$.

\section{Instruments}

A computerized experimental paradigm of metamemory was used (Zortea, Jou, \& Salles, 2014), shown in Figure 1, which evaluated monitoring processes (JOLs) and memory control (STA), as well as the memory performance, through the study of pairs of words (target cue).

\section{Procedure}

Data collection. The participants responded, on-site and individually, to the experimental paradigm of metamemory, in suitable rooms in the university or in schools, taking, on average, 40 minutes. For the administration of the paradigm, the E-prime 2.0 software was used (Schneider, Eschman, \& Zuccolotto, 2002), and the items were presented using a 15.6' screen notebook, using the Arial font, size 32, in black, on a white background. The items were presented randomly in all the stages. A short training session was undertaken prior to the recall stage, with cues, in three tests not included later. The task was begun regardless of the performance.

In the condition of delayed JOLs, 80 pairs of target cue words were presented, 40 of which were semantically related (e.g. wheel - tire) and 40 of which were not (e.g. jaguar - flower), one at a time, for four seconds each. The semantically-related pairs were taken from the databases of Salles et al. (2008). The participant had to memorize the pairs for a later memory test. Following that, only the cues for each one of the 80 pairs of words were re-presented, one at a time, for judgment. For each cue, the question was put: 
"How likely do you judge it that you will be able to remember the second word of this pair, a little while from now?'. Each participant responded verbally, so as to facilitate the way of answering, using a Likert scale (1 - I am sure that I won't remember; 2 - It is unlikely that I will remember; 3 - It is fairly likely that I will remember; 4 - I am sure that I will remember), and the researcher noted the response using a numerical keyboard. In the condition of immediate JOLs, the only change was that the judgments on the Likert scale were made after the presentation of each pair for study, and not in a single block.

For both the conditions, the 80 cue words were subsequently re-presented for recall, with the cue read out loud for the corresponding target. The participant was asked: "What is the second word in the pair?". The answer was given out loud and recorded by the researcher using the notebook's keyboard. As well as the answer "I don't know", the participant could make a guess if she had doubts. Following that, in a self guided restudy, 40 pairs of words (20 semantically-related, and 20 not), selected randomly from the initial 80, were re-presented. The participant was requested to press a button in order to advance to the next pair, as soon as she judged that she had memorized the item sufficiently for a later re-test. Finally, the procedure of cuedrecall was repeated, although the data from this recall were not analyzed in this study.
The paradigm provided the dependent measurements of the study, which consisted of the JOLs' magnitude, the JOLs' relative and absolute accuracy, the score of cued-recall, time allocated to restudying the pairs, and correlations between the time of restudy and JOLs between time of restudy and cued-recall. These measurements will be detailed in the data analysis. Using a comparative group design, with convenience sampling, four distinct groups were formed, in accordance with inter-participant manipulations of the variables of Age (young and intermediate-age adults) and Type of JOL (immediate and delayed JOLs), with the participants' allocation to each JOL condition being random. The variable of Type of Item (semantically-related and not) was manipulated intra-participant.

Data analysis. The magnitude of the JOLs refers to the mean value for the learning judgments. The JOLs' relative accuracy was obtained using the Type 2 Signal Detection Theory (SDT) (Higham, Perfect, \& Bruno, 2009; Stanislaw \& Todorov, 1999). Sensitivity curves were constructed which related correct answers (attributing high JOL to an item, and this being correctly recalled, and attributing low JOL to an item incorrectly recalled) and false alarms (attributing high JOL to an incorrectly recalled item). A good relative accuracy is represented by high rates of correct answers and low rates of false alarms. The coefficient of accuracy was the area under the curve (AUC) (Stanislaw

Condition - delayed JOLs

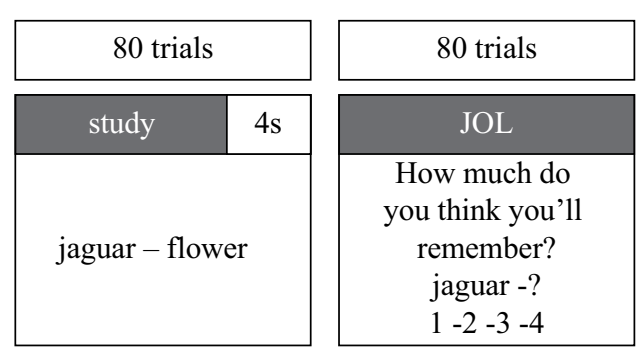

Condition - immediate JOLs

\begin{tabular}{|c|c|}
\hline \multicolumn{2}{|c|}{$\begin{array}{c}80 \text { trials for study } \\
\text { and JOL }\end{array}$} \\
\hline study & $4 s$ \\
\hline \multicolumn{2}{|c|}{ jaguar - flower } \\
\hline \multicolumn{2}{|c|}{ JOL } \\
\hline \multicolumn{2}{|c|}{$\begin{array}{c}\text { How much do } \\
\text { you think you'll } \\
\text { remember? } \\
\text { jaguar -? } \\
1-2-3-4\end{array}$} \\
\hline
\end{tabular}

Common stages for both the conditions

\begin{tabular}{|c|c|c|}
\hline \multicolumn{1}{|c|}{80 trials } & 40 pre-selected trials & 80 trials \\
\hline cued-recall & restudy & cued-recall \\
\hline $\begin{array}{c}\text { What is the second } \\
\text { word in the pair? } \\
\text { jaguar }-?\end{array}$ & jaguar - flower & $\begin{array}{c}\text { What is the second } \\
\text { word in the pair? } \\
\text { jaguar }-?\end{array}$ \\
\hline
\end{tabular}

time

Figure 1. Schematic illustration of the experimental paradigm of metamemory for the conditions of delayed and immediate JOLs. The time for each test was unlimited, except for the study phase ( $4 \mathrm{~s}$ each test). JOL = judgments of learning; $1=I$ am sure that I won't remember; $2=$ it is unlikely that I will remember; $3=$ it is fairly likely that I will remember; $4=$ I am sure that I will remember. 
\& Todorov, 1999), a non-parametric measurement which is ideal for scales with few items, as was the case. The values varied from .5 (random recall) to 1.0 (maximum accuracy). Absolute accuracy consisted of the difference between the mean magnitude of the JOLs, which was transformed into a proportion (values from 0 to 1 ), and the scores of cued-recall. The lower the difference, the more accurate the judgment.

The scores for cued-recall consisted of the proportion (values from 0 to 1 ) of pairs of words which were correctly recalled. The mean time spent restudying the pairs was also calculated, presented in seconds, and Pearson correlations between time restudying and magnitude of the JOLs (STA based in the JOLs), and biserial correlations between time restudying and score for cued-recall (STA based on the cued-recall) were made. Fisher's z-transformation scores are provided below for these correlation values. Descriptive analyses (means and standard error) and inferential analyses (analyses of variance) were used, so as to test the study hypotheses.

\section{Ethical Considerations}

The project was approved by the Research Ethics Committee of the Instituto de Psicologia of the Universidade Federal do Rio Grande do Sul (Process no. 21717/2011).

\section{Results}

In relation to the monitoring, in the analysis of the JOLs' magnitude, a mixed ANOVA was undertaken, with the interparticipant factors of Age (young adults and intermediate-age adults) and Type of JOL (immediate or delayed), and the intra-participant factor of Type of item (semanticallyrelated or not). A principal effect was found for Type of JOL $\left(F[1,40]=6.08 ; p=.018 ; \eta^{2}=.13\right)$, such that the magnitude of the immediate JOLs was greater $(M=2.56 ; S E=0.09)$ than that of the delayed JOLs $(M=2.24 ; S E=0.09)$. There was also a principal effect for Type of JOL $(F[1,40]=186.77$; $\left.p<.001 ; \eta^{2}=.82\right)$, with related items $(M=2.82 ; S E=0.07)$ receiving higher JOLs than non-related items $(M=1.98$; $S E=0.07)$, which is in accordance with the literature (Carroll et al., 1997). There was no principal effect for Age $(F[1,40]=1.39 ; p<.244)$. In addition to this, there was interaction (Figure 2) between Type of JOL and Type of item $\left(F[1,40]=53.04 ; p<.001 ; \eta^{2}=.57\right)$, such that the magnitude of the immediate JOLs was greater $(M=3.20 ; S E=0.10)$ than that of the delayed JOLs $(M=2.44 ; S E=0.10)$ only for related items $\left(F[1,40]=32.29 ; p<.001 ; \eta^{2}=.45\right)$. Non-related items did not differ by Type of JOL (immediate JOL: $M=1.91 ; S E=0.11$; delayed JOL: $M=2.05 ; S E=0.10$ ). Another interaction (Figure 2) was between Age and Type of $\operatorname{JOL}\left(F[1,40]=8.69 ; p=.005 ; \eta^{2}=.18\right)$, such that only intermediate-age adults $\left(F[1,40]=12.43 ; p=.001 ; \eta^{2}=.24\right)$ showed immediate JOLs which were higher $(M=2.67$; $S E=0.14)$ in comparison with delayed JOLs $(M=1.98$; $S E=0.14)$. In addition to this, only in the condition of delayed JOLs $\left(F[1,40]=8.80 ; p=.005 ; \eta^{2}=.18\right)$ did the young adults express greater JOLs $(M=2.50 ; S E=0.11)$ in comparison with intermediate-age adults.

Another mixed ANOVA, with the same factors, was implemented regarding the scores for cued-recall. The results indicated principal effects for Age $(F[1,40]=4.46 ; p=.041$; $\left.\eta^{2}=.10\right)$, Type of JOL $\left(F[1,40]=6.24 ; p=.017 ; \eta^{2}=.13\right)$ and Type of item $\left(F[1,40]=176.41 ; p<.001 ; \eta^{2}=.81\right)$. As a result, a higher score for recall was found, respectively, for young adults $(M=0.51 ; S E=0.03)$ in comparison with intermediate-age adults $(M=0.40 ; S E=0.04)$, immediate JOL $(M=0.52 ; S E=0.04)$ compared with delayed JOLs $(M=0.39 ; S E=0.04)$ and related items $(M=0.60 ; S E=0.03)$ in comparisons with items not related semantically $(M=0.31 ; S E=0.03)$. One interaction (Figure 2$)$ between Type of JOL and Type of item $(F[1,40]=31.90 ; p<.001$; $\left.\eta^{2}=.44\right)$ indicated that only semantically-related items were more frequently remembered in the condition of immediate JOLs $(M=0.73 ; S E=0.04)$ in comparison with delayed JOLs $(M=0.47 ; S E=0.04)(F[1,40]=24.64 ; p<.001$; $\left.\eta^{2}=.38\right)$. Non-related items did not differ in accordance with the conditions of the JOLs (immediate JOLs: $M=0.31$; $S E=0.05$; delayed JOLs: $M=0.30 ; S E=0.04)$. Another interaction (Figure 2) between Age and Type of item $\left(F[1,40]=5.27 ; p=.027 ; \eta^{2}=.12\right)$ indicated that young adults had higher scores for recall $(M=0.39 ; S E=0.04)$ than intermediate-age adults $(M=0.22 ; S E=0.05)$ only for non-related items $\left(F[1,40]=6.67 ; p=.014 ; \eta^{2}=.14\right)$. Young and intermediate-age adults recalled similar quantities of related items (young adults: $M=0.63 ; S E=0.03$; intermediate-age adults: $M=0.57 ; S E=0.04$ ).

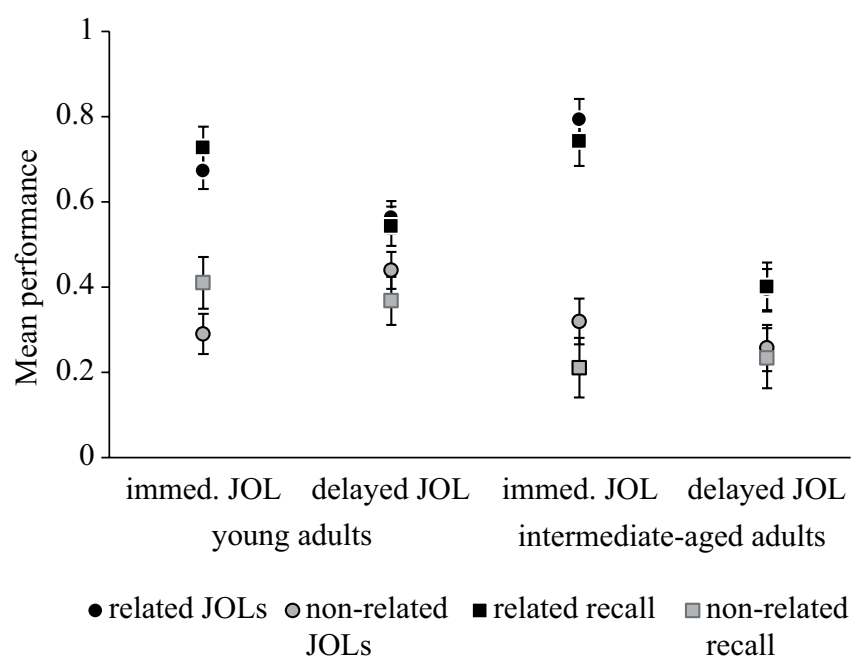

Figure 2. Mean values of the magnitudes of the JOLs and the scores for cued-recall, in accordance with the factors of Age (young adults and intermediate-age adults), Type of JOL (immediate and delayed) and Type of Item (semantically-related or not). The measurement of magnitude of the JOLs was transformed in proportional values (from 0 to 1 ), such that it could be comparable with the scores of cued-recall. 
The relative accuracy of the JOLs, using the measurement of the area under the ROC curve (AUC), was subjected to a two-way ANOVA 2 (Type of JOL: immediate or delayed) $\mathrm{X} 2$ (Age: young and intermediate-age adults). There was a principal effect for Type of JOL $(F[1,40]=24.43 ; p<.001$; $\eta^{2}=.38$ ), such that immediate JOLs were less accurate than delayed JOLs. There was no principal effect for Age $(F[1,40]=.04 ; p<.851)$, although there was interaction (Figure 3$)$ between Type of JOL and Age $(F[1,40]=19.29$; $\left.p<.001 ; \eta^{2}=.32\right)$. Only for young adults $(F[1,40]=53.07$; $\left.p<.001 ; \eta^{2}=.57\right)$ were there differences in terms of relative accuracy between immediate JOLs $(M=0.69 ; S E=0.02)$ and delayed JOLs $(M=0.92 ; S E=0.02)$, in favor of the former. The age groups differed in terms of accuracy both for the immediate JOLs $\left(F[1,40]=8.56 ; p=.006 ; \eta^{2}=.18\right)$ and delayed JOLs $\left(F[1,40]=1.84 ; p=.002 ; \eta^{2}=.21\right)$, this being a combined interaction. In the condition of immediate JOLs, young adults were less accurate than intermediate-age adults $(M=0.79 ; S E=0.03)$. In the condition of delayed JOLs, the effect was the opposite, with intermediate-age adults being less accurate $(M=0.81 ; S E=0.03)$ than young adults. In relation to the absolute accuracy of the JOLs, a two-way ANOVA 2 (Type of JOL: immediate and delayed) $\mathrm{X} 2$ (Age: young adults and intermediate-age adults), there were no principal effects or interaction between the factors. It was observed that the mean magnitudes of the JOLs and the scores for cued-recall were relatively similar, which indicates, generally speaking, good capacity for estimating the quantity of items to be recalled.

The Study-Time Allocation (STA), measure of memory control, was initially examined in terms of time restudying. A 3-way mixed ANOVA 2 (Type of Item) X 2 (Type of JOL) $\mathrm{X} 2$ (Age) was used. A principal effect was observed for Type

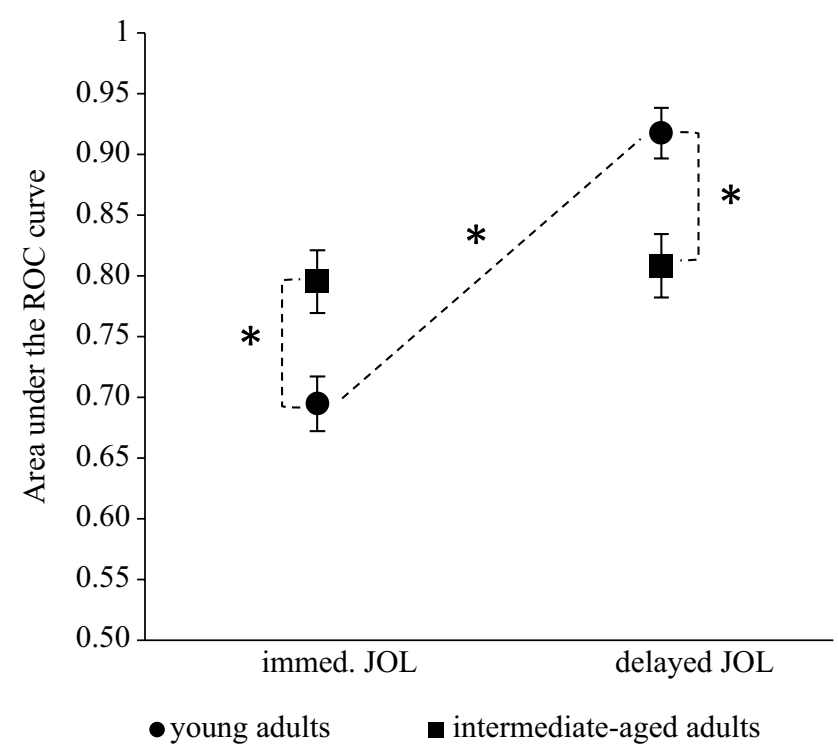

Figure 3. Mean values of relative accuracy (area under the ROC curve) as a function of Age and Type of JOL. * = simple significant effects at the level of $p<.05$. of item $\left(F[1,40]=61.92 ; p<.001 ; \eta^{2}=.61\right)$, but not for Age $(F[1,40]=1.48 ; p=.230)$ or Type of JOL $(F[1,40]=1.91$; $p=.175)$. Neither were statistically significant interactions found. As a result, items which were not semantically related $(M=9.4 ; S E=0.8)$ were restudied for more time than the items which were related $(M=5.8 ; S E=0.5)$.

Subsequently, in order to test the "monitoring affects control" hypothesis in adults of different ages, memory control was evaluated based on correlational measures (STA based in the JOLs and STA based on cued-recall). All the participants showed negative correlations, as expected. After transformation into Fisher's z scores, the variables were close to a normal curve, according to Shapiro-Wilk tests $(p>.05)$. Firstly, a two-factor ANOVA was undertaken 2 (Age: young adults and intermediate-age adults) X 2 (Type of JOL: immediate and delayed) regarding the STA measurement based in the JOLs. There was a principal effect for Age $\left(F[1,40]=4.83 ; p=.034 ; \eta^{2}=.11\right)$ and Type of JOL $\left(F[1,40]=11.96 ; p=.001 ; \eta^{2}=.23\right)$. Young adults, in general, showed greater STA based in JOLs than intermediate-age adults. In addition to this, immediate JOLs were associated with a lower STA based in JOLS, than were delayed JOLs.

One interaction (Figure 4 ) was found $(F[1,40]=12.57$; $\left.p=.001 ; \eta^{2}=.24\right)$, such that young adults who made delayed JOLs had greater STA based in JOL $(M=-0.71 ; S E=0.05)$ than those who made immediate JOLs $(M=-0.32$; $\left.S E=0.05 ; F[1,40]=29.87 ; p<.001 ; \eta^{2}=.43\right)$. This effect did not occur for intermediate-age adults (immediate JOLs: $M=-0.40 ; S E=0.06$; delayed JOLs: $M=-0.40 ; S E=0.06$; $F[1,40]=.003 ; p=.954)$. When the groups were compared according to Type of JOL, the STA based in the JOLs of the young adults was greater than that of the intermediate-age adults $\left(F[1,40]=17.04 ; p<.001 ; \eta^{2}=.30\right)$, although only in the condition of delayed JOLs, without significant differences for immediate JOLs $(F[1,40]=.88 ; p=.354)$.

The correlational measurement of STA based on the cued-recall was also examined through a two-way ANOVA 2 (Age) X 2 (Type of JOL). There was a principal effect for Age $\left(F[1,40]=5.17 ; p<.028 ; \eta^{2}=.11\right)$, but not for Type of JOL $(F[1,40]=1.36 ; p<.251)$, such that young adults had higher correlations of STA based on cued-recall than intermediate-age adults. One interaction (Figure 4) was also found $\left(F[1,40]=6.46 ; p<.015 ; \eta^{2}=.14\right)$. Young adults who made delayed JOLs presented significantly greater $\left(F[1,40]=11.97 ; p<.001 ; \eta^{2}=.23\right)$ STA based on cued-recall $(M=-0.92 ; S E=0.06)$ than intermediate-aged adults $(M=-0.56 ; S E=0.08)$. There were no differences between the groups in the condition of immediate JOLs (young adults: $M=-0.82 ; S E=0.07$; intermediate-age adults: $M=-0.84 ; S E=0.08 ; F[1,40]=.03 ; p<.854)$. Besides this, greater STA based on cued-recall was observed in immediate JOLs than delayed JOLs, although only for intermediate-age adults $\left(F[1,40]=5.83 ; p<.020 ; \eta^{2}=.13\right)$, it being the case that young adults did not have differences between the conditions $(F[1,40]=1.15 ; p<.289)$. 


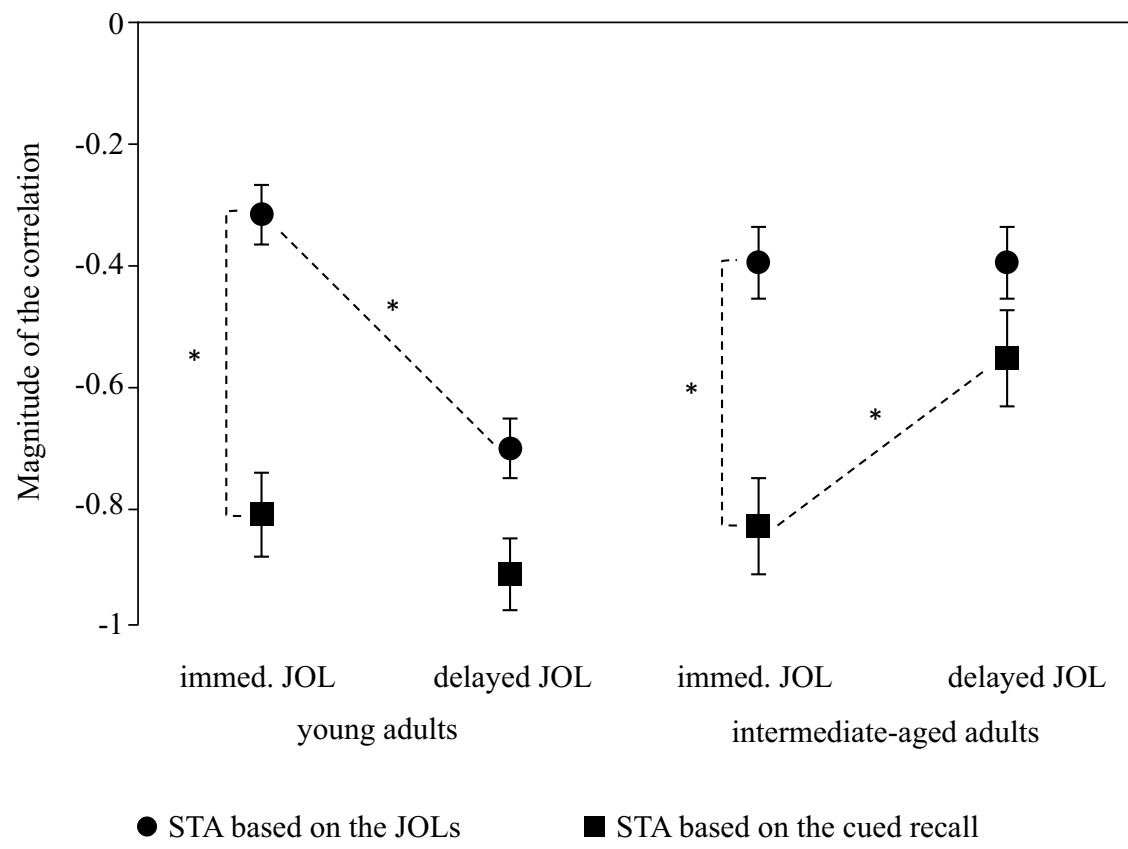

Figure 4. Mean values of the measurements of STA based in the JOLs and STA based on recovery with cue, in accordance with Type of JOL (immediate and delayed) and Age (young adults and intermediate-age adults). ${ }^{*}=$ simple significant effects at the level of $p<.05$.

\section{Discussion}

Previous studies (Carroll et al., 1997; Connor et al., 1997) indicated differences regarding the memory monitoring, according to factors such as characteristics of the items (related pairs generate higher JOLs), the time of the metamnemonic judgments (JOLs made after some time of the study phase tended to be more accurate) and the age of the participants (older adults are less accurate in their judgments than young adults). Differences regarding age were also indicated in the memory control mechanisms (Dunlosky \& Connor, 1997), in favor of young adults. This study brought advances in the understanding of the processes of monitoring and control of memory as it investigated adults of intermediate age, in comparison with young adults, evaluating the joint influence of these factors. The findings reinforce and expand some hypotheses found in the literature.

In relation to the magnitude of the JOLs, the sensitivity effect regarding the semantic relation between the words of the pair studied was found in both the conditions (delayed and immediate JOLs). That is, pairs which were semanticallyrelated received greater JOLs than unrelated pairs. Carroll et al. (1997) did not find this effect in delayed JOLs after 24 hours after the study phase. These authors suggested that JOLs should be made based both on a metacognitive knowledge held for a long time (semantically-related pairs are more easily remembered), and in relation to the online memory monitoring. Koriat (2007) described this information respectively with intrinsic and mnemonic cues. Thus, immediate JOLs, as they are closer to the phase of study and codification of the information, are more sensitive to the characteristics of the stimulus. Furthermore, among the hypotheses, it is understood that JOLs made days after the study are based on long-term information, as reviewed by Rhodes and Tauber (2011), such that characteristics of the codification should have less influence. However, a delay of 15 to 20 minutes for the JOL still demonstrated a sensitivity effect for the type of item.

One unanticipated result was that semantically-related pairs were more easily recovered in the condition of immediate JOLs than delayed. One a posteriori analysis showed that the interval between the study and the cued recall of the pairs was, on average, nearly two times greater in the condition of delayed JOLs in comparison with immediate JOLs. One can, therefore, raise the hypothesis of a fall in the memory trace. In the delayed condition, retroactive interferences (e.g., presentation of other items after the study) may have hindered the strategic use of the semantic relationship. On the other hand, non-related items, as a result of being, in general, more difficult (as they do not have information facilitating the use of semantic strategies for codification), may have been less frequently codified. There would not, therefore, be a memory trace for the majority of them, independently of the condition of the JOLs. Rhodes and Tauber (2011) conclude that it is possible that JOLs should be accompanied by retrieval practice, as a form of memory monitoring. As a result, delayed JOLs may have been sensitive to the fall in the memory trace as a result of time and, therefore, their magnitude was lower in comparison with the immediate JOLs. For non-codified items, as it is supposed the case may be for a large proportion of the non-related pairs, the retrieval practice also has diagnostic ability in relation to the probability of subsequently recalling the information. 
Studies have demonstrated the protective role of associative information against memory decline or deficits (Patterson, Light, Van Ocker, \& Olfman, 2009). It is emphasized that only intermediate-age adults, through delayed JOLs, reported lower chances, on average, of remembering the items than through immediate JOLs. As there were differences in the score for recall between the conditions of immediate and delayed JOLs, it is possible to argue that intermediate-age adults who made delayed JOLs were more realistic regarding their memory performance.

As expected for relative accuracy, delayed JOLs were more accurate in estimating performance in the cued-recall than immediate JOLs, which corroborates the models of the literature (Rhodes \& Tauber, 2011). This finding amplifies the effect of the delayed JOLs using, in this case, the measurements of the area under the ROC curve (AUC). Some advantages of this measurement are: non-parametric property, greater stability and reduction of overestimation effects in comparison with the Gama correlation classically used (Maniscalco \& Lau, 2012). In the case of absolute accuracy, on the other hand, a more detailed method would be the analysis of the calibration curves (Dunlosky $\&$ Metcalfe, 2009), which was not possible due to the low frequency of responses for some values of the Likert scale of the experiment.

However, the effect of the delayed JOLs on the relative accuracy was observed only for young adults. It is possible to suppose that intermediate-age adults, even if they achieve good accuracy in their judgments (mean $\cong 0.8$ ), make JOLs based on different cues from those used by young adults. In some form, these cues maintained their monitoring skill constant, independently of the condition. Previous experiences with situations of memorizing without external assistance (such as teachers) for judging their performance could be related to this result (Johnson \& Halpern, 1999). In order to clarify this point, further studies with intermediate-age adults need to be undertaken.

In addition to this, one bias of the present study was that the sample of intermediate-age adults was made up entirely of teachers from the public teaching network, with higher education completed. It is asked what the role of professional and educational level is in the developing of metamemory and metacognition in adults. However, it is noteworthy that an a posteriori correlational analysis did not show a relation between years of study and the dependent variables studied here. These characteristics of the sample may be related to the findings shown here, although the literature requires a more in-depth understanding regarding this issue.

It was also observed that, in general, participants in the study applied more time studying items judged as of low probability to be remembered and to items which were not correctly remembered, according to the STA measurements based on the JOLs and the STA based on cued-recall. This is in accordance with the "monitoring affects control" hypothesis (Thiede \& Dunlosky, 1999). One of the present study's contributions is the interaction between age and types of JOLs, in particular the finding that young adults supposedly based their STA more on their judgments and on how much they remembered the items, than intermediate-age adults. Dunlosky and Connor (1997) had already reported this in a study with adults and older adults. These authors suggested that older adults have greater difficulty in coordinating processes of monitoring and control, terminating the study prior to the norm of study being achieved, for example. One hypothesis is considered that this also occurs with people in the second phase of adult life.

Besides this, the STA of young adults who made delayed JOLs had a stronger relationship with the magnitude of the judgments than those who made immediate JOLs. As this result is in accordance with the data of relative accuracy presented, it is supposed that delayed JOLs, as they are more diagnostic of the memory performance (more accurate), are also more reliable at the time of the restudying of the topics for future memory recall testing. There is support in the literature regarding this relationship (Hines, Touron, \& Hertzog, 2009). It is noteworthy that as much the STA based in the JOLs as that based in the cued-recall was significantly lower for the intermediate-age adults in the condition of delayed JOLs. It may be concluded that this reduction in the use of monitoring for guiding the control of memory, found in older adults (Dunlosky \& Connor, 1997) has its beginning prior to the age of 60 years old, even if the capacity for monitoring is maintained.

Through the present investigation, it can be concluded that monitoring and control of memory occur differently as a result of the previous relationship between the elements of an item (pairs of words which are, or are not, semantically related) and of the point at which the judgment is made (immediately or delayed). Some of these differences seem to interact with age, even in intermediate-age adults, which indicates slightly distinct effects occurring prior to old age. Thus, this study shows advances in the national literature, such as the use of an online evaluation of metamemory in intermediate-age adults.

\section{References}

Ariel, R., Dunlosky, J., \& Bailey, H. (2009). Agendabased regulation of study-time allocation: When agendas override item-based monitoring. Journal of Experimental Psychology: General, 138(3), 432-447. doi:1.1037/a0015928

Carroll, M., Nelson, T. O., \& Kirwan, A. (1997). Tradeoff of semantic relatedness and degree of overlearning: Differential effects on metamemory and on longterm retention. Acta Psychologica, 95(3), 239-253. doi:1.1016/S0001-6918(96)00040-6

Connor, L. T., Dunlosky, J., \& Hertzog, C. (1997). Age-related differences in absolute but not relative metamemory accuracy. Psychology and Aging, 12(1), 50-71. doi:1.1037/0882-7974.12.1.50 
Dunlosky, J., \& Connor, L. T. (1997). Age differences in the allocation of study time account for age differences in memory performance. Memory \& Cognition, 25(5), 691-70. doi:1.3758/bf03211311

Dunlosky, J., \& Metcalfe, J. (2009). Metacognition: A textbook of cognition, educational, life span, and applied psychology. Thousand Oaks, CA: Sage.

Higham, P. A., Perfect, T. J., \& Bruno, D. (2009). Investigating strength and frequency effects in recognition memory using type-2 signal detection theory. Journal of Experimental Psychology: Learning, Memory, and Cognition, 35(1), 57-8. doi: $1.1037 / \mathrm{a} 0013865$

Hertzog, C., \& Dunlosky, J. (2011). Metacognition in later adulthood: Spared monitoring can benefit older adults' self-regulation. Current Directions in Psychological Science, 20(3), 167-173. doi:1.1177/0963721411409026

Hines, J. C., Touron, D. R., \& Hertzog, C. (2009). Metacognitive influences on study time allocation in an associative recognition task: An analysis of adult age differences. Psychology and Aging, 24(2), 462-475. doi:1.1037/a0014417

Johnson, S. K., \& Halpern, A. R. (1999). Prediction accuracy of young and middle-aged adults in memory for familiar and unfamiliar texts. The American Journal of Psychology, 112(2), 235-257. doi:1.2307/1423352

Koriat, A. (2007). Metacognition and consciousness. In P. D. Zelazo, M. Moscovitch, \& E. Thompson (Eds.), The Cambridge handbook of consciousness (pp. 289-326). New York, NY: Cambridge University Press.

Koriat, A. (2012). The relationships between monitoring, regulation and performance. Learning and Instruction, 22(4), 296-298. doi:1.1016/j.learninstruc.2012.01.002

Maniscalco, B., \& Lau, H. (2012). A signal detection theoretic approach for estimating metacognitive sensitivity from confidence ratings. Consciousness and Cognition, 21(1), 422-43. doi:1.1016/j.concog.2011.09.021

Martin, M., \& Zimprich, D. (2005). Cognitive development in midlife. In S. L. Willis \& M. Martin (Eds.), Middle adulthood: A lifespan perspective (pp. 179-206). Thousand Oaks, CA: Sage.

Nelson, T. O., \& Narens, L. (1990). Metamemory: A theoretical framework and new findings. In G. H. Bower (Ed.), The psychology of learning and motivation: Advances in research and theory (Vol. 26, pp. 125-173). San Diego, CA: Academic Press.

Ofen, N., \& Shing, Y. L. (2013). From perception to memory: Changes in memory systems across the lifespan. Neuroscience and Biobehavioral Reviews, 37(9, Part B), 2258-2267. doi:1.1016/j.neubiorev.2013.04.006

Patterson, M. M., Light, L. L., Van Ocker, J. C., \& Olfman, D. (2009). Discriminating semantic from episodic relatedness in young and older adults. Aging, Neuropsychology, and Cognition, 16(5), 535-562. doi:1.1080/13825580902866638
Rhodes, M. G., \& Tauber, S. K. (2011). The influence of delaying judgments of learning on metacognitive accuracy: A meta-analytic review. Psychological Bulletin, 137(1), 131-148. doi:1.1037/a0021705

Salles, J. F., Holderbaum, C. S., Becker, N., Rodrigues, J. C., Liedtke, F. V., Zibetti, M. R., \& Piccoli, L. F. (2008). Normas de associação semântica para 88 palavras do português brasileiro. Psico, 39(3), 362-37.

Schneider, W., Eschman, A., \& Zuccolotto, A. (2002). E-prime reference guide. Pittsburgh, PA: Psychology Software Tools.

Stanislaw, H., \& Todorov, N. (1999). Calculation of signal detection theory measures. Behavior Research Methods, Instruments \& Computers, 31(1), 137-149. doi:1.3758/BF03207704

Thiede, K. W., \& Dunlosky, J. (1999). Toward a general model of self-regulated study:An analysis of selection of items for study and self-paced study time. Journal of Experimental Psychology: Learning, Memory, and Cognition, 25(4), 1024-1037. doi:1.1037/0278-7393.25.4.1024

Zortea, M., Jou, G. I., \& Salles, J. F. (2014). Tarefa experimental de metamemória para avaliar monitoramento e controle de memória. Psico-USF, 19(2), 329-344. doi:1.1590/1413-82712014019002012

Maxciel Zortea holds a Ph.D. in Psychology from the Universidade Federal do Rio Grande do Sul.

Graciela Inchausti de Jou holds a Post-doctorate in Developmental Psychology from the Universidade Federal do Rio Grande do Sul.

Jerusa Fumagalli de Salles is an Adjunct Professor of the Instituto de Psicologia of the Universidade Federal do Rio Grande do Sul.

Received: Apr. 3, 2014

1st Revision: Sep. 4, 2014

2nd Revision: Nov. 14, 2014

Approved: Dec. 18, 2014

How to cite this article:

Zortea, M., Jou, G. I., \& Salles, J. F. (2015). Memory monitoring and control in young and intermediate-age adults. Paidéia (Ribeirão Preto), 25(61), 241-249. doi:10.1590/1982-43272561201512 